\title{
Design and construction of the Centre National d'Art et de Culture Georges Pompidou
}

\author{
P. B. AHM. F. G. CLARKE, E. L. GRUT \& P. RICE
}

\section{Mr Ahm, Mr Clarke, Mr Grut and Mr Rice}

The Centre Pompidou is one of the most important buildings to be built in Western Europe in recent times. It is important because of the way it came about, sponsored as it was by the late President Pompidou himself and intended as a monument to the Fifth Republic. It is important because of the function it is intended to perform, being an active national centre for art and culture, a workshop for future creations. It is important because of its location in the middle of historic Paris, in a district which was nevertheless depressed and shabby. The impact the Centre has had on this district is beyond description.

150. It is important because of its architecture, which is direct, functional and brutal. People either love it or hate it, but they always react to it.

151. The other special points of this project are that it was won in competition, and that it was done in France.

152. The fact that the competition was won by a combined team of engineers and architects, and also designed and implemented by that team, has never been fully understood and recognized by the public and the press, especially the architectural press who apparently cannot conceive that engineers can play any creative part in a project and that engineering is an art form, aiming at synthesis and only making use of scientific analysis and knowledge as tools.

153. The architecture of the building is strongly controlled, but it does clearly reflect the creative part played by engineers in concept, design and details.

\section{Mr C. C. Banks, G. Maunsell and Partners}

This is a most remarkable building. The main frames are described as a mechanism. Did this cause any great problems with deflexions, particularly as I believe all the transverse forces were taken out to the ends of the building?

155. In the Paper, the floor beams are described as being pinned on one side of the main beams. This again is rather more flexible than is usual. Did it cause any problems?

156. Would the Authors like to mention any points about flexibility, temperature movements or movements in general which are encountered on this building which one would not normally expect to meet?

Paper published: Proc. Instn Civ. Engrs, Part 1, 1979, 66, Nov., 557-593. 
Ms M. Law, Ove Arup and Partners

I joined Ove Arup and Partners in 1974, when the project had already started, and I was involved in the later stages of negotiations on fire safety.

158. First, as this was a public building and a large number of members of the public would be using it, there was great concern about public safety. There had been a disastrous fire in a dance hall in France, with a number of young people killed, and there was a whole new stringent climate where public safety was concerned.

159. Secondly, the fire brigade had a major responsibility to stop city conflagrations. Their great concern was to be able to control and contain a fire as efficiently and as quickly as possible, and at least risk to the firemen.

160. Thirdly, this was an important and valuable structure, with important and valuable contents.

161. Under all three headings the fire safety design was very important. There were a number of measures adopted to meet the objectives, but because most fire safety measures solve more than one problem at a time, it is often confusing to know which measures are doing which job. This is one of the reasons why it is difficult for engineers to understand what fire authorities are getting at. That is a problem in every country, not just France.

162. There was a package of measures, all interacting. As far as public safety was concerned the important thing was the detection and alarm system, that there were proper escape routes, that the whole building was fitted with sprinklers, and that the building was divided into compartments with fire-resistant walls and floors. These measures also helped the fire brigade in their problem of fire containment.

163. As far as the building structure is concerned, the sprinklers are an enormous help in reducing fire exposure, but in designing the fire protection of the structure it was assumed that the sprinklers would not work.

164. For the internal structure a fairly conventional approach was made on fire exposure by assuming a standard fire. There was conventional fire cladding. The only problem was to find thicknesses which did not cover up the shape of the structure. The only unconventional approach was that the critical condition was defined by calculation rather than by subjecting the structure to test.

165. On the external structure, the approach was quite non-conventional. Fire exposure was not the standard fire exposure, but one calculated for structures outside a building where they are free to cool to the outside air as well as being heated by the fire and the flames from the windows. The critical condition was again calculated because it could not be tested. The protection was also non-conventional and there were a variety of solutions. The main columns were water-filled, the water being used to keep the steel cool. There was also water cooling by means of water spray on some of the members, and the gerberettes were shielded by panels in the façade. Spacing was another way of protecting the elements, the distance being nearly $8 \mathrm{~m}$. Because of the compartmentation of the building, we could assume that only one part of the external structure would be heated at any one time, and therefore some of the bracing could be sacrificed without endangering the overall stability of the building.

166. At that time, attitudes on design of fire safety generally were beginning to change towards a more quantified design approach, and we were able to incorporate some of the approach in the design. I think that if we were doing it now we would get a much more favourable reception, with acceptance of at least 
quantification of fire exposure, and possibly of quantification of the effectiveness of the various safety measures, if only we had enough statistical data to make such an assessment.

\section{Dr J. D. Harrison, The Welding Institute}

Because of the unusual size of the castings used in this building, and the extensive use of welding associated with them, the Welding Institute was called in at an early stage to assess the toughness of the castings themselves and also of the welds. We had to bear in mind that there was little redundancy in the building, and so failure of any one casting or weld could be disastrous.

168. As described in the Paper, full thickness fracture toughness tests were carried out, both on the plain castings and on the heat-affected zones and weld metals.

169. Initial difficulties with the toughness were solved by changing the heat treatment of castings and by changing the composition of the weld metals.

170. Finally, we achieved a situation where the advantage of fracture mechanics came to the fore. This is that it provides the engineer with a relationship between the applied stress, the material, and the defect size which could cause the structure to fail. We reached the stage when we could say that there was a tolerance for buried cracks of at least $10 \mathrm{~mm}$ dia., and we felt confident that such cracks could be detected by the careful non-destructive testing that was used.

171. However, one of the difficulties with castings is in the quality control. One cannot measure the properties of the casting: one has to measure the properties in an appendix which is cast with it, and because the appendix is much smaller than the casting, the two do not have identical properties. We had therefore to use correlations between the properties of the appendices and the true fracture toughness which was measured on the main casting.

172. A final measure was to subject every member containing a casting to an overload test before erection into the building. The gerberettes were strapped back to back and jacked apart so that they were subject to overload. The beams themselves were also loaded by jacking. At the end of the programme we had great confidence in the safety of this rather unusual material which had not been used extensively before in a structure of this type.

\section{Mr W. J. Haley, William Haley and Partners}

This building has many parallels with offshore steel structures, such as the use of tubulars and nodes, and the need for crack opening displacement tests for preventing brittle fracture in the steel plates with thicknesses exceeding $60 \mathrm{~mm}$. I would like to know why the steel columns were made from spun cast tubes, and not from seam-welded rolled steel plate as is usual for offshore structures.

174. Mr Rice has said that the design aims to express in its detail a confidence and variety characteristic of Victorian structures. I suggest that such confidence remains with us today in the design of offshore structures.

175. I would like the Authors to say something more about the application of penalties in the design contract if the estimated construction cost differed from the actual cost by more than $12 \%$. Do they think that a similar measure should be introduced in the UK? 
Mr D. E. Key, Consulting Engineers Partnership

I believe that the water-filled columns were exposed. Were they subjected to freezing?

177. Concerning the responsibilities of the design team, my experience is that as soon as a design team based on different firms and professions is held responsible for anything, it ceases to be a team and becomes a group of individuals. Usually, by definition, if anything goes wrong the Engineer is held responsible. Would the Authors please comment?

Mr B. Corbett, Ove Arup and Partners

The basement is about the same size as the building at approximately $300000 \mathrm{~m}^{3}$. Information has been published on the perimeter wall ${ }^{\mathbf{8 , 1 9 , 2 0}}$ and the barrette foundations. ${ }^{9}$

179. I should like to consider the grouting - the third element in the foundation works. This basement is very deep and one of the largest urban excavations in Europe. It is subject to flooding in the event of the River Seine overtopping its banks, in which case water will back up the sewers. The techniques adopted for the perimeter grout curtain were essentially those developed by Ischy et al. ${ }^{21,22}$ using the tube-a-manchette method. The purpose of the grouting was to reduce the seepage into the basement during the excavation stage and to reduce the risk of flotation. The final design stage was proceeding on the preparation of the APD report while the foundation contracts were in progress.

180. Figure 29 shows the tube-à-manchette method. The technique involves drilling a hole, inserting a tube and filling the annulus with a weak grout. There are a

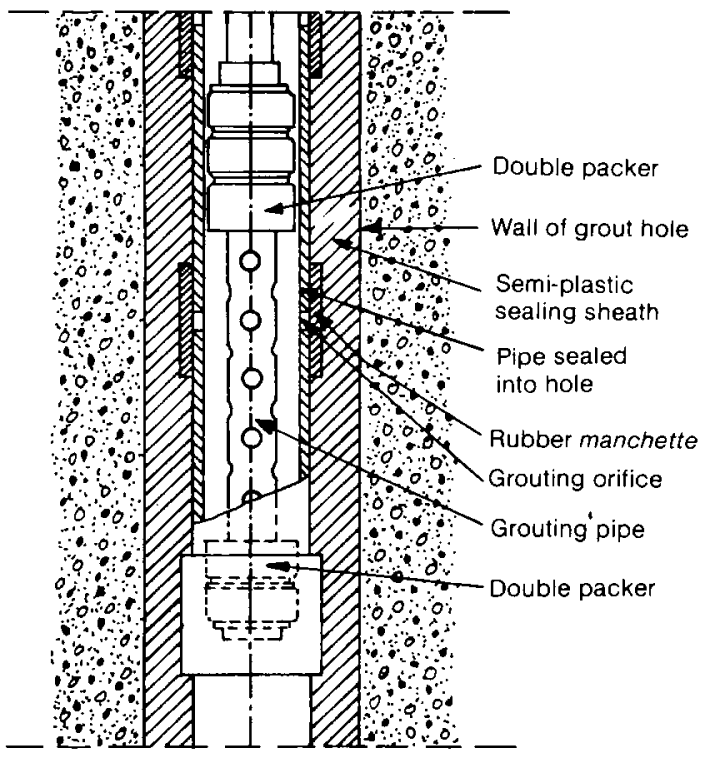

Fig. 29. Tube à manchette 
series of holes in this tube, each of which is surrounded by a rubber sleeve. A second tube is lowered inside the first and this has packers which are located above and below one of the sets of holes. Grout is pumped down the central tube and the application of pressure forces the grout past the rubber sleeve so that it ruptures the weak grout and penetrates the soil or rock.

181. After grouting the efficiency is tested by pumping water under pressure down the hole at each level, again using packers at top and bottom.

182. We found that something peculiar was happening, because although the ground appeared to be reasonably uniform the results we were getting were not uniform. We would find a low permeability and then a meter gap with considerable water loss, then another zone of low permeability and so on.

183. What had gone wrong was really quite simple. In trying to speed up the work the packer spacing had been opened out to such an extent that the packer spanned two sleeves at one time and there could be a gap of $0.7-0.8 \mathrm{~m}$ completely untreated. The solution was to close the packer spacing so that the grout passed into the ground at each discrete horizon.

184. This is just one example of the hundreds or even thousands of problems on the whole job, and it was a direct consequence of trying to do things rather too quickly.

\section{Mr B. P. Wex, Freeman Fox and Partners}

$I$ understand that saddles were attached to tubes with longitudinal welds, and the longitudinal welds were taking the shear forces. What did you do about the cavity between the saddle and the tube as far as the place where you would put the transverse welds in was concerned? How did you seal this? Obviously this would form a corrosion trap.

186. How do you envisage dealing with the maintenance of such a complex structure?

187. Concerning the achievement of costs within $12 \frac{1}{2} \%$, and maintenance of programme, what does one do about strikes and go-slows by the workforce? Can such a situation not arise?

\section{Mr Ahm, Mr Clarke, Mr Grut and Mr Rice}

In answer to Mr Banks, the building was restrained by the floors acting between the end gables, and the horizontal movement at the centre of the floors, if measured against the end of the gable, was about $2 \mathrm{~cm}$ maximum. This is a theoretical maximum because the principal force creating this horizontal movement is the stability force of the columns. That was a function of the lack of true of the columns and the amount of eccentricity placed on the columns. We took fairly generous assumptions when we were calculating this.

189. The actual movement at the end of the building came to another $2 \mathrm{~cm}$ at the top. The principal problem of movement in the building was the vertical deflexion of the beams, which in their centre under maximum load could deflect up to $20 \mathrm{~cm}$. That obviously placed a lot of constraints, particularly on the glazing and other elements when they came back into the building away from the gable ends. But, as with all problems, once one knows clearly what the problem is it is relatively straightforward to solve, and in the end it did not impose too much of a constraint.

190. The maximum differential movement obtained at the top between the first 
floor and the ground was $\pm 2 \mathrm{~cm}$ at either end of the building. That was the reason why at the first floor the ceiling height is $10 \mathrm{~m}$ and not $7 \mathrm{~m}$.

191. Mr Haley asks about the spun cast columns. One reason for this was political: it was a French firm that made them and we were trying to get as much French in the contract as we could. The other reason was that spun cast columns are cast in the same external mode and they have a continuous surface; although this can be achieved with welded steel columns, the surface obtained was more true from a visual point of view. It was an architectural reason for preferring this solution. Furthermore, the column thicknesses vary from $85 \mathrm{~mm}$ down to $40 \mathrm{~mm}$ and obviously cast steel gave us greater flexibility in putting them where we needed them.

192. There are questions from Mr Haley and Mr Wex on the design cost of $\pm 12 \frac{1}{2} \%$. Up to 1973 in France they had scandals galore because there was never any proper design team control. Many projects cost two and three times more than they were originally estimated to cost. This caused a lot of problems and the French Government and the profession brought in a new system. We were used as the guinea pigs. The system comprises a very comprehensive and detailed scale of fees. There are all kinds of complexities and it is compulsory now on all public contracts. The tolerance varied on this particular building by $\pm 12 \frac{1}{2} \%$. The design team has to take that responsibility. They are responsible for keeping the cost within that tolerance. If they do not get it their fees are reduced accordingly. If they overestimate the costs and the final cost is, say, $50 \%$ lower than the estimate, they are penalized.

193. In France they do not have separate firms of quantity surveyors. Usually architects and engineers work together. We accept Mr Key's point that in his experience as soon as a design team based on different firms and professions is held responsible for anything, it ceases to be a team and becomes a group of individuals. Indeed we all have from time to time experienced that if anything goes wrong it is usually the engineer who is held responsible.

194. In the new engineering rules in France, it is just this division of responsibility that the authorities have tried to avoid by insisting on one agreement between the client and the design team. The design team decides who among their members should be the mandataire: it is not automatically the architect, it can be any member of the team depending on the nature of the work. However, before any agreement is signed, the responsibilities of each member have to be clearly defined. The architect could blame the engineer or vice versa if anything goes wrong. However, they don't because if the job is a success it is to the design team's credit and if it fails it is to their detriment. The client refers to that team and does not and will not interfere in domestic issues among its members. It is for the members to sort themselves out and from our experience in France, the system works. Although in any relationship there are ups and downs and in-fighting, these are less evident in France than in the UK where each member of the so-called team has a separate appointment with the client. French designers are forced to work together and they have the right to decide which other professionals they wish to work with. Under the new regulations, the client cannot say that he wants firm $A$ to be his architect, firm $\mathrm{B}$ to be his engineer or firm $\mathrm{C}$ to be his quantity surveyors or economists. The designers are urged right from the outset to select for themselves other professionals with whom they are mutually compatible. There are no forced marriages which can sometimes result in recriminations.

195. We think it is much better and much clearer for the client and from the 
point of view of the designers to work in a system where the cost conditions are clearly understood by both sides. It not only introduces discipline into the design team, it also introduces discipline into the client because they know they will be spoiling their chances of penalizing the design team if they interfere too much and introduce too many changes. From that point of view it is a very beneficial system.

196. How do we finish on time? Well, France is a very different country from the UK. In answer to Mr Wex, on this particular job we had very few strikes and goslows. A lot of the labour is immigrant labour from Morocco, Algeria, Tunisia and Portugal and the unions are not very strong. If there was a strike due to unforeseen circumstances the architects and engineers would not be penalized for the ensuing delay and extra costs.

197. Mr Key asks about freezing the columns. Obviously there are anticorrosion inhibitors and anti-freeze in the columns. In fact, there is only about $40 \%$ water; the rest is all sorts of other things to keep the system operational. We also have a pump for the columns to mix up the water so that it remains non-separated during its life. We found when we came to service the pumps for the first time that a number of them had been put in incorrectly and the jackets had corroded because of some problems with the mix in the water. We had a bit of ice form on some of the columns, so it was just as well we went round servicing.

198. Mr Wex asks about corrosion protection of the steel. There was a seal to prevent and contain corrosion inside. Problems of corrosion were related to the moving parts; they did not, in fact, move very much, but they had the presumption of moving built into the design. We used seals, re-sealed them and added a further, final, seal; a great deal of careful analysis of the way in which the joint had been put together was carried out, in order to guarantee as far as possible that there would be full protection. The steel has a ten-year corrosion seal, and it is the intention of the clients to replace the top coat every seven years. In fact, maintenance has not been a problem: the building is so successful, the client is actually looking after it.

\section{References}

19. Corbett B. O. Current design practice applied in differing ground conditions for diaphragm walls, contiguous piles and anchorages. In: A review of diaphragm walls. Institution of Civil Engineers, London, 1977, 17-26.

20. DeRbyshiRE P. H. Report of discussion on current design practice applied in differing ground conditions for diaphragm walls, contiguous piles and anchorages. In: A review of diaphragm walls. Institution of Civil Engineers, London, 1977, 27-28.

21. Ischy E. and Glossop R. An introduction to alluvial grouting. Proc. Instn Civ. Engrs, 1962, 21, Mar., 449-474.

22. CAmbefort H. Injections des sols. Editions Eyrolles, Paris, 1967, vols I and II. 